\title{
Central giant cell granuloma in anterior maxilla
}

\author{
Shwetang Goswami ${ }^{1}$, Haripriya², \\ Yashwanth Yadav ${ }^{3}$, Ram Mohan ${ }^{4}$
}

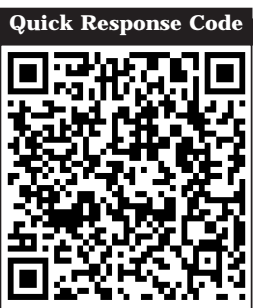

doi: $10.5866 / 2014.621570$

1\&3Senior Lecturer

${ }^{2 \& 4}$ Post Graduate Student

Department of Oral and Maxillofacial Surgery

Kamineni Institute of Dental Sciences,

Sreepuram, Narketpally, Nalgonda (Dist) - 508254

\section{Article Info:}

Received: J anuary 9, 2014

Review Completed: February 10, 2014

Accepted: March 7, 2014

Available Online: J uly, 2014 (www.nacd.in)

(C) NAD, 2014 - All rights reserved

\section{Email for correspondence:}

shwetang14@gmail.com

\section{Introduction}

Giant cell granuloma (GCG) was first described by J affein 1953 as "giant cell reparative granuloma", but currently does not referred as reparative, because of its locally destructive. ${ }^{1}$ It is classified as peripheral if it affects the extremities and central if it develops in the midline (being the least common type). It is a relatively rare entity. Accounted for $7 \%$ of the maxillary tumors (the preferred location is the incisor region, and more frequently in the mandible than the maxilla). ${ }^{2}$ It is more common in children and young adults, with a slight predominance in females. ${ }^{3}$ As etiological factors have been related several factors, especially local irritants

\section{ABSTRACT:}

Giant cell granuloma is an uncommon bony lesion in the head and neck region, most commonly affecting the maxilla and mandible. Although it is a benign disease process, it can also be locally destructive. Surgery is the traditional and still the most accepted treatment for giant cell granuloma. The case described here involved the anterior maxilla.

Key words: central giant cell granul oma, maxilla, residual cyst. 
front teeth region since two months. Patient gave a history of trauma 2 months back. Later the patient devel oped a swelling in the same region and got her upper front teeth extracted al ong with pus drainage. One month later patient developed swelling again which increased in size gradually.

On clinical examination, a single diffuse swelling was seen measuring approximately $2 \times 3 \mathrm{~cm}$ extending from midline of upper lip and philtrum to left nasal ala obliterating the naolabial fold on left side (Figure 1). On intraoral examination, 21, 22 are missing. A single well defined swelling measuring $2 \times 3 \mathrm{~cm}$ approximately was seen extending from 11 to 23; involving marginal, papillary and attached gingiva and extending palatally (F igure 2). On pal pation, the swelling was soft and tender. A clinical diagnosis of radicular cyst or residual cyst or aneurysmal bone cyst, pyogenic granuloma, gingival fibroma was made.

An orthopantamograph (OPG) and occlusal radiograph were taken where OPG showed a radiolucent region extending from 21 to 23 (Figure 3). Computed tomography scan (CT) showed the mass extending inferiorly into the body of the maxilla uptoalveolus (Figure 4). Medially, it crossed the midline of the maxilla, distally it extended up to 23 and superiorly it extended up to the pyriform aperture, suggesting complete involvement of the anterior maxilla. Two separate histopathological examinations confirmed Central Giant Cell Granuloma. A provisional diagnosis of radicular cyst, residual cyst, glandular odontogenic cyst, aneurysmal bone cyst was made.

An incisional biopsy was performed and specimen was sent for histopathologic examination (Figure 5). The $\mathrm{H}$ and $\mathrm{E}$ stained sections show presence of numerous multinucleated giant cells in a back ground of cellular stroma composed of round to spindle shaped cells. These multinucleated giant cells were dispersed uniformly throughout the connective tissue stroma, suggestive of central giant cell granuloma. Hence a final diagnosis of central giant cell granuloma was made.

\section{Discussion:}

GCG has been defined by the World Health Organization as an intra-osseous lesion consisting of cellular fibrous tissue that contains multiple foci of hemorrhage, aggregations of multinucleated giant cells, and, occasionally, trabeculae of woven bone. ${ }^{5}$
GCG accounts for $<7 \%$ of all benign lesions of the mandible and maxilla in tooth-bearing areas. The mandible, anterior to the first molar teeth, is the most commonly affected site. ${ }^{6}$ Central GCG (e.g., GCG of the mandible and maxilla) is less common than peripheral GCG of the extremities. ${ }^{7}$ GCG affects children and adults, and may occur at any age, but is most commonly seen in the first 3 decades. It is more frequent in females than in males. The etiology of the GCG still remains to be defined. It has been reported that the origin of this lesion could be triggered by trauma or inflammation. The common effects of GCG are: painless swelling that remains undetected until facial asymmetry, impaired nasal breathing, and loosening or displacement of teeth. Localized swelling is an important clinical feature. The swelling is smooth, and pal pation can reveal a rubbery, elastic sensation where the bone has thinned. Although the lesion is expansile and invasive, it does not usually involve the perineural sheets. For this reason, paresthesia is not usually observed in these patients. ${ }^{8}$

The clinical behavior of GCG ranges from a slowly growing asymptomatic swelling to an aggressive lesion. When GCG is a slow-growing lesion, it can be asymptomatic and discovered on a routine X-ray, while the rapidly expanding, aggressive variety is characterized by pain and facial swelling. These fast growing lesions also havea high rate of recurrence. It has been reported that recurrence is usually found when the lesion perforates the cortical plates to involve the surrounding soft tissue. ${ }^{9}$ There have been reports of recurrence as early as 3 years and as late as 22 years. ${ }^{10}$

Radiologic features vary from undefined destructive lesions to a well-defined, multilocular appearance. Teeth or roots displacement are the most consistent features which are well appreciated on CT than on plain film. ${ }^{11}$ However none of these radiological features is specific for GCG. It is important to bear in mind that theX-ray appearance of the lesion is not pathognomonic and may be confused with many other lesions of the maxilla and the mandible.

Histologically, multinucleated giant cells, in a cellular vascular stroma, and often new bone formations are detected. The osteoclast-like giant cells have a patchy distribution and are usually associated with areas of haemorrhage. 

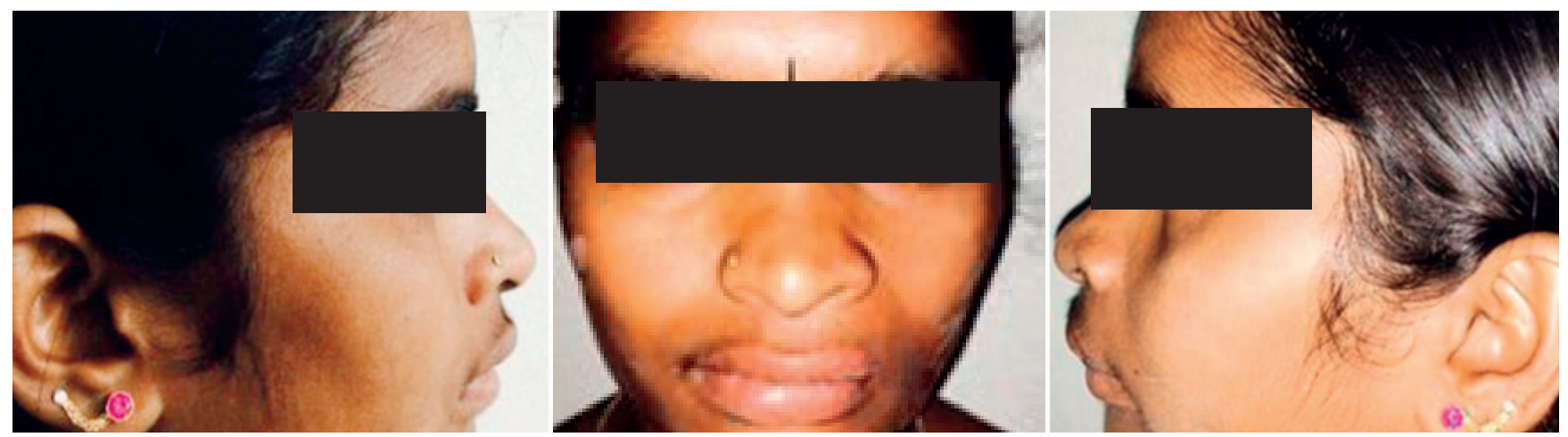

Figure 1: Profile pictures of the patient showing swelling of upper lip on left side obliterating nasolabial fold.

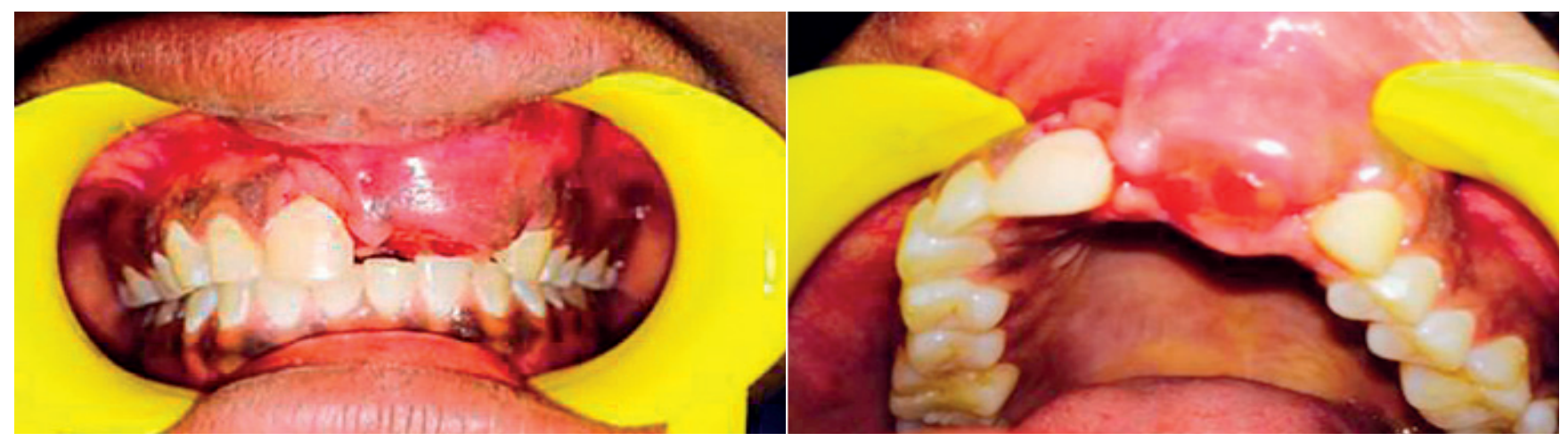

Figure 2: intraoral extent of lesion

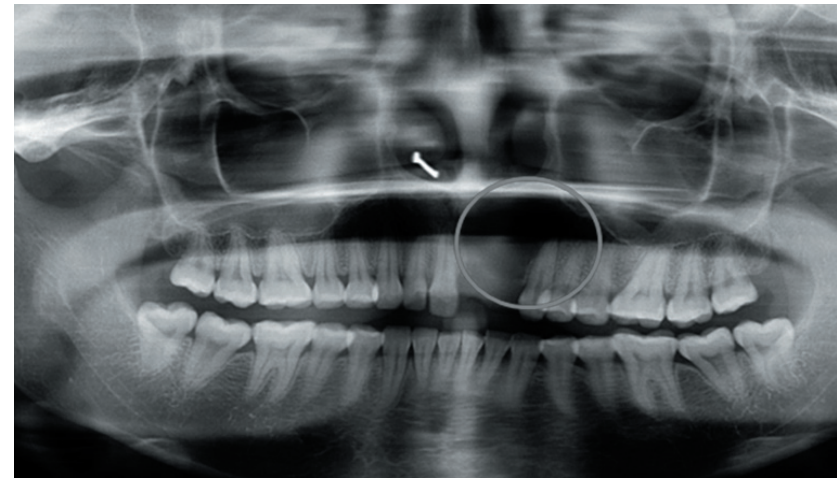

Figure 3: OPG showing radiolucent lesion.

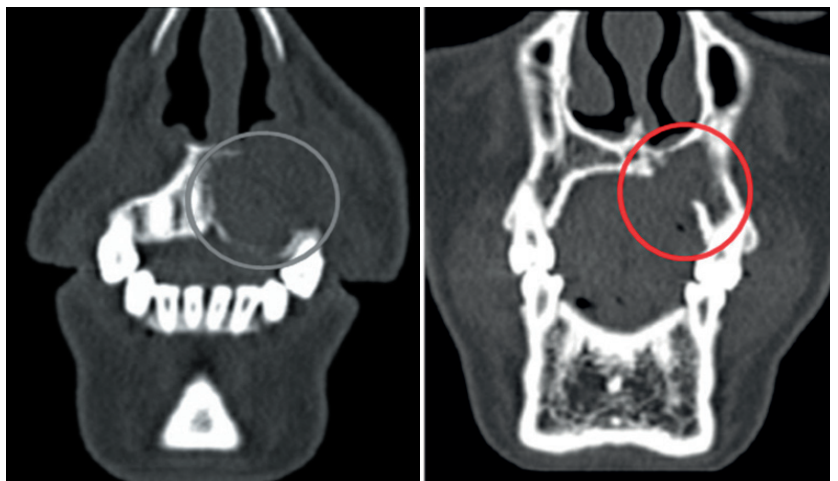

Figure 4: CT scan showing extent of lesion
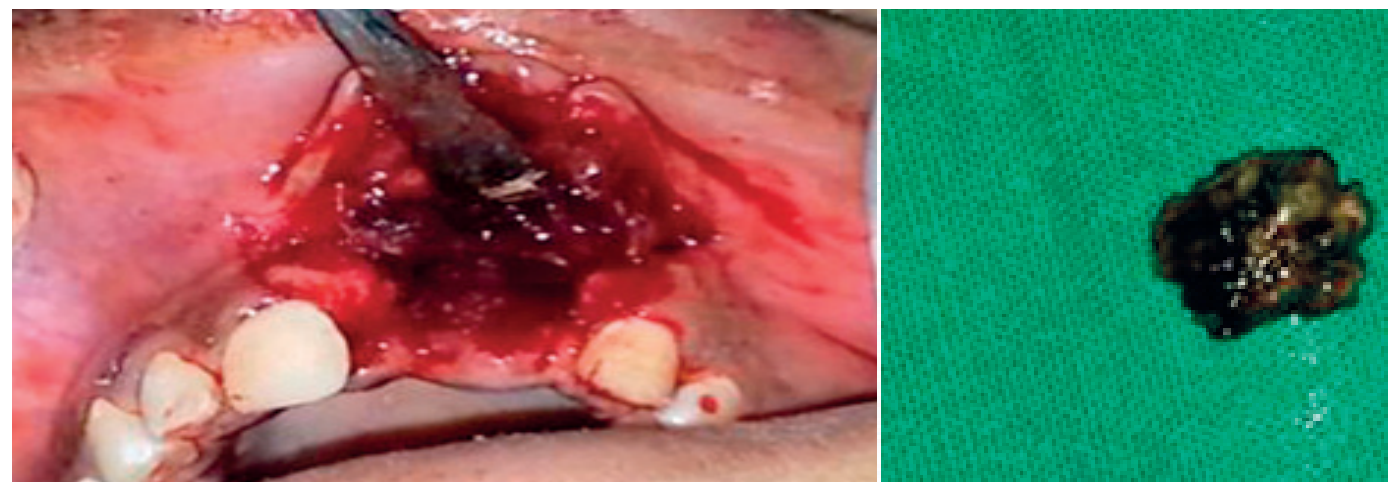

Figure 5: incisional biopsy done and specimen sent for biopsy 
Ultrastructurally, the proliferating cells include spindle-shaped fibroblasts, myofibroblasts, and inflammatory mononuclear cells. ${ }^{12}$ GCG is a vascularized lesion that shares many features with the aneurysmal bone cyst. Differentiation from the latter can also be difficult histologically. However, the aneurysmal bone cyst is characteristically composed of honeycomb blood-filled spaces with a lining of flat non-endothelial cells. ${ }^{13}$ Brown tumour of hyperparathyroi dism is histologically very similar to GCG. Thus, all patients with suspected GCG should have serum calcium, phosphate and alkaline phosphatase levels evaluated, to exclude the possibility of hyperparathyroidism. The nonossifying fibroma is histologically very similar to the GCG which can, however, be differentiated from the latter since the granuloma- like aggregate of giant cells and the fibrous stroma found in GCG, are not typical features of non-ossifying fibroma.

Treatment of GCG of the maxilla and mandible with calcitonin has also been reported. GCGs have been successfully treated with calcitonin, in various concentrations, for at least 1 year, and complete remission of GCG has been observed, without signs of recurrence. However, calcitonin therapy can be complicated by side-effects, such as hypocalcaemia and secondary hyperparathyroi dism. ${ }^{14} \mathrm{~F}$ urthermore the relatively long duration of treatment can be more intolerable, for some patients, especially children. Another form of treatment for GCG consists in weekly intra-lesional injections with corticosteroids, successful results have been reported in the literature. ${ }^{15}$ Steroid treatment was first suggested by Body et al., in $1981 .{ }^{16}$ Corticosteroid treatment is, however, relatively contraindicated in certain medical conditions, such as diabetes mellitus, peptic ulcer, and generalized immuno-compromised states. Non-surgical therapies for GCG are probably good treatment options for small slow-growing lesions, while successful treatment of painful, large, and rapidly growing lesions is still more likely to be achieved by surgical removal. ${ }^{6}$

\section{Conclusion:}

GCG is a relatively rare entity of benign histologic nature but can have a very aggressivelocal behavior. A definitive diagnosis is reached by biopsy of the lesion. It should be present in the differential diagnosis in all expansive osteolytic lesions affecting the jaw or maxilla, such as pyogenic granuloma, gingival fibroma, fibrosarcoma and distant metastases of tumors. Its treatment includes from removal of it to the simple intralesional injection of corticosteroids or the use of calcitonin or INF- $\alpha$, always with clinical and radiological control due to its high rate of recurrence. Given the failure of conservative treatment, management be should an aggressive resection and reconstruction, when it is possible.

\section{REFERENCES:}

1. J affe HL. Giant cell reparative granuloma, traumatic bone cyst, and fibrous (fibro-oseous) dysplasia of the jaw bones. Oral Surg Oral Med Oral Pathol 1953; 6:159-175.

2. Comert E, Turanli M, Ulu S. Oral and intralesional steroid therapy in giant cell granuloma. Acta Otolaryngol.2006; 126:664-666.

3. Motamedi MH, Eshghyar N, J afari SM, Lassemi E, Navi F, Abbas FM, et al. Peripheral and central giant cell granulomas of the jaws. A demographic study. Oral Surg Oral Med Oral Pathol Oral Radiol Endod.2007; 103:39-43.

4. Kaban LB, Troulis MJ, Ebb D, August M, Hornicek FJ, Dodson TB. Antiangiogenic therapy with interferon alpha for giant cell lesions of thejaws. J Oral Maxillofac Surg.2002; 60:1103-1111.

5. Kramer IRH, Pindborg J J, Shear M. Histological typing of odontogenic tumors. Second Edn. Berlin: Springer-Verlag 1991.

6. Bataineh $A B, A I-K$ hateeb $T$, Rawashdeh AB. The surgical treatment of central giant cell granuloma of the mandible. J Oral Maxillofac Surg 2002; 60:756-761.

7. Khafif A, Krempl G, Medina J E. Treatment of GCG of the maxilla with intralesional injection of steroids. Head Neck 2000; 22:822-825.

8. Fechner RE, Stacey EM. Atlas of tumor pathology; tumors of the bones and joints. Armed Forces Institute of Pathology 1992; 181-182.

9. Minic A, Stajcic Z. Prognostic significance of cortical perforation in the recurrence of central giant cell granulomas of the jaws. J Craniomaxillofac Surg 1996; 24:104-107.

10. Cassatly MG, Greenberg AM, Kopp WK. Bilateral giant cell granuloma of the mandible: report of case. J ADA 1988; 117:731-733.

11. Bodner L, Bar-Ziv J . Radiographic features of central giant cell granuloma of the jaws in children. Pediatr Radiol 1996; 15:148-151.

12. Rosai J. Ackerman's surgical pathology. 8th Edn. St. Louis,MO: C.V. Mosby Co; 1996.

13. Prein J Remagen W, Spiessl B, Uehlinger E. Atlas of tumors of the facial skeleton. New York: Springer Verlag; 1986.

14. De Lange J, Rosenberg AJ, Van den Akker HP, Koole R, Wirds J J , Van den Berg H. Treatment of central giant-cell granuloma of the jaw with calcitonin. Int J Maxillofac Surg 1999; 28:372-376.

15. Rajeevan NS, Soumithran CS. Intralesional corticosteroid injection for central giant cell granuloma. A case report. Int J Oral Maxillofac Surg 1998; 27:303-306.

16. Body J J , J ortay AM, De J ager R, Ardichvili D. Treatment with steroids of a giant cell granuloma of the maxilla.J Surg Oncol 1981; 16:7-13. 